\title{
CONTINUED SMOKING VERSUS SPONTANEOUS QUITTING AMONG PREGNANT WOMEN LIVING IN A HIGH RISK ENVIRONMENT
}

\author{
Peter Balázs ${ }^{1}$, Andrea Grenczer ${ }^{2}$, Ildiko Rákóczi ${ }^{3}$ Kristie L. Foley ${ }^{4}$ \\ ${ }^{1}$ Institute of Public Health, Faculty of Medicine, Semmelweis University, Budapest, Hungary \\ ${ }^{2}$ Faculty of Health Sciences, Semmelweis University, Budapest, Hungary \\ ${ }^{3}$ Debrecen-Nyiregyhaza University, Debrecen, Hungary \\ ${ }^{4}$ Wake Forest University Medical School, Comprehensive Cancer Center, Winston-Salem, NC, USA
}

\begin{abstract}
SUMMARY
Objectives: In Hungary, 37\% of women living in poverty were smokers in 2012. There are no valid data of pregnant women's spontaneous smoking cessation.

Methods: Our retrospective cohort study (2009-2012) targeted the most underdeveloped regions with an estimated 6-8.5\% of Roma population. The sample $(\mathrm{N}=12,552)$ represented $76 \%$ of the target population i.e. women in four counties in a year delivering live born babies. Chi-square probe and multivariable logistic regression model $(p<0.05)$ were used to assess relationship between socio-demographic characteristics and spontaneous cessation.

Results: Prior to pregnancy, the overall smoking rate was $36.8 \%$. That of women in deep poverty and Roma was $49.7 \%$ and $51.1 \%$, respectively. $70.3 \%$ of smokers continued smoking during the pregnancy. Among them $80.6 \%$ lived in deep poverty. Spontaneous quitting rate was $23.0 \%$. Factors correlated with continued smoking included being Roma $(O R=1.95)$, undereducated $(O R=2.66)$, living in homes lacking amenities $(O R=1.48)$, and having regularly smoking partner $(O R=2.07)$. Cessation was promoted by younger age $(\leq 18$ years) $(O R=0.18)$, being married $(O R=0.50)$, and the first pregnancy.

Conclusions: Tailored cessation programmes are needed for Roma, older, low-income, and multiparous women who are less likely to quit on their own. Engaging husbands/partners is essential to reduce smoking among pregnant women and second-hand smoke exposure.
\end{abstract}

Key words: tobacco smoking, pregnant women, spontaneous quitting, high risk environment, Roma population

Address for correspondence: P. Balázs, Institute of Public Health, Semmelweis University, Ulloi u. 26, 1189 Budapest, Hungary. E-mail: balazspeter@windowslive.com

https://doi.org/10.21101/cejph.a5048

\section{INTRODUCTION}

Maternal tobacco smoking during pregnancy is one of the most harmful risk factors with increased probability of preterm birth (PTB), low birth weight (LBW) and small for gestational age (SGA) birth of live-born neonates (1). A recent study indicated that there is strong association between maternal smoking habits during the pregnancy and socioeconomic deprivation (2). Additionally, women whose partners were smokers were more likely to smoke throughout pregnancy (3). Ethnic minority groups, such as Roma in Europe, are disproportionately living in deprived communities, their rates of tobacco use are high, and they experience significant exposure to second hand smoke (SHS) (4). As such, these populations are at high risk for unfavourable obstetrical outcomes (5-8). According to the European Union (EU) Framework for National Roma Integration Strategies up to 2020, Hungary has the 4th largest Roma ethnic minority among the EU countries (Bulgaria 10.33\%, Slovakia 9.17\%, and Romania 8.32\%). In 2011, 315,000 individuals self-identified as Roma, however, the estimated average number of Roma in Hungary is 700,000 (9).
The underdeveloped north-eastern region of the country has the highest estimated concentration of Roma, i.e. $6.0-8.5 \%$ of the local population (10).

One strategy to reduce the population prevalence of smoking is to introduce strong tobacco control policies (11). Hungary's first tobacco control legislation enacted in 1999 limited smoking to a few public places (12). Its amendment (in force since January 1,2012) strengthened the original Act and extended the ban for all confined public places (except psychiatric wards and correctional facilities) (13). Recent surveillance studies of the impact of national tobacco bans have shown that while the general population benefits from such bans, the effects on neonatal health and maternal smoking during pregnancy may be limited (14).

Hungary's average prevalence of adult smoking was $32.3 \%$ for males and $23.5 \%$ for females in 2012 (15). Among persons 13-15 years old, $31 \%$ were current smokers (boys 33\%, girls $28 \%$ ). When stratified by socioeconomic status, among adult males and females living in poverty, $54 \%$ and $37 \%$ are regular smokers. Likewise, among males who did not completed 8 years of basic school, smoking rates are $45 \%$ compared to $32 \%$ 
among males who completed 8 years and 20\% among males with higher education. Corresponding female data are $22 \%$, $26 \%$, and $18 \%$ (16).

Lacking relevant data about the smoking behaviour of pregnant women in Hungary, especially low-income pregnant women, we conducted a population based cross-sectional study in the country's most underdeveloped north-eastern region. Hungary has a total of 19 counties, plus the capital of Budapest. The four target counties of this research (Borsod-Abauj-Zemplen, Heves, Nograd, Szablocs-Szatmar-Bereg) were ranked 20, 19, 17, and 14 by gross domestic product (GDP) per capita values, with the higher ranking meaning the lowest GDP (17).

Since 1927, Hungary has a special Maternity and Child Health Service (MCHS), which employs precinct-based registered nurses for a population of 2,000-3,000. During the last three decades, they were traditionally active in assessing smoking habits of pregnant women and informal counselling on tobacco cessation. An extended meta-analysis of worldwide published 42 clinical studies (1987-2007) with more than 15,000 participants indicated that brief interventions delivered by nurses in health promotion or cardiac rehabilitation are more effective than longer interventions with multiple contacts (18). A recent review based on 24 studies which focused specifically on nursing interventions to promote smoking cessation during pregnancy confirmed that most studies achieved some decrease in smoking by interventions (19). The review emphasized that interventions need to be user-friendly, flexible, accessible, culturally- sensitive, age appropriate, and effective.

Hungary recently (2014) extended the MCHS nurses' competency list to include minimal intervention for smoking cessation by implementing competencies of the 5A's model (Ask, Advise, Assess, Assist, Arrange) (20). This model is recognized by the World Health Organization and the US Surgeon General as low-cost, evidence-based strategies for promoting cessation $(21,22)$. Additionally, pregnancy is one of the best motivators to quit smoking at least until delivery. Our data, collected prior to the 2014 legislation allows our team to assess information about spontaneous and successful quitting tobacco smoking habits during the pregnancy. Thus, these data provide foundational data on which to evaluate the future effectiveness of the MCHS minimal intervention programme of smoking cessation under the most difficult socioeconomic circumstances.

In a US-based study, spontaneous smoking cessation during the pregnancy "was less likely in women who gave previous births, had a husband or partner who smoked, were born in the United States, were black (non-Hispanic, non-Portuguese), had less than a high school education, were highly addicted, reported lower perceived risk to the foetus, and reported too many other problems in life to stop" (23). Using positive approach, spontaneous quitters during the pregnancy among low-income ethnic minority women had higher self-confidence, smoked fewer cigarettes a day and were younger (24).

\section{MATERIALS AND METHODS}

This is a retrospective cohort study (2009-2012) of all women who delivered live born babies in Hungary's four north-eastern counties. Based on hospital records of all live-born cases regis- tered by local MCHS nurses, there were 16,519 total deliveries during the study period. Deliveries outside of obstetrical wards rarely occur in this country. As a result of a collaboration agreement with health authorities, the MCHS nurses were trained to collect data to inform the baseline evaluation. They conducted in-person, anonymous surveys with 12,552 mothers, which represented $76 \%$ of the target population $(\mathrm{N}=16,519)$. Ethnicity admitted $85.2 \%$ of the sample.

\section{Measurement}

Demographic and biometric data of mothers and infants were obtained from the local MCHS. The overwhelming majority $(96.8 \%)$ of pregnant women attended the MCHS in the first $(74.5 \%)$ and the second $(22.3 \%)$ trimester. For calculation of gestational weeks and the neonates' birth weight, multiple birth cases were excluded. LBW was defined as $<2,500$ grams, PTB as $<37$ gestational weeks. Maternal body mass index (BMI) values ( $\mathrm{kg}$ bodyweight $/ \mathrm{m}^{2}$ of body height) were broken down as underweight $(<18.5)$, normal (18.5-24.9), overweight (25-29.9), and obese ( $\geq 30.0$ ). Ethnicity as Roma or Hungarian (i.e. non-Roma Caucasian population) was self-determined. We used ethnicity as a main binary category while testing differences in the deep poverty subsample.

Socioeconomic questions concerned level of education, housing conditions, family income per month per capita, and labour market position. Basic education comprises eight classes while middle level education indicates completed vocational training or secondary school, higher education means college or university graduation. Housing without amenities was defined as no connection to the water supply mains, sewage system, and operational individual heating. Partial amenities meant one or two missing conditions. Family status was measured as married, divorced, single (never married) mothers and those living as cohabitants with a partner. Employment was measured as full-time or parttime paid employment. Mothers without employment included women receiving any kind of social benefits (except unemployment benefits), and students of all educational facilities.

Without legal poverty level, there are used annually published data about poverty of the Hungarian Central Statistical Office. Based on national data of the Organization for Economic Cooperation and Development (OECD) 50\% (in the European Union $60 \%$ ), the median income equals the income poverty level. In Hungary, the median income/month/consumption unit increased from HUF 60,000 in 2009 to 84,000 in 2012 (25). Using a conservative approach, we defined deep poverty as < $50 \%$ of the 2009 value.

Lifestyle questions included alcohol and tobacco use, nutritional characteristics, and drinking coffee. Only $0.9 \%(n=116)$ admitted consuming any alcoholic drinks at least $1-2$ times a week during the whole pregnancy, thus we did not used this variable in the analyses. Questions about dietary habits concerned fruits, vegetables and dairy products consumed every day, only once a week or a month, and never. The frequency of drinking coffee was categorized the same way.

Regular prenatal smoking (prior to and during the pregnancy) was defined as smoking at least 1 cigarette a day. Second-hand smoke (SHS) was defined as having ever been exposed at home while pregnant in confined spaces. Smoking cessation during 
pregnancy was defined as self-reported prompt quitting at the time when women learned they were pregnant. At the time of the survey, smoking cessation counselling was available outside of the MCHS system and free of charge for all through the social health insurance system. Thus, we explored if regular smokers used this service.

\section{ANALYSIS}

The following measures were dichotomized for analytical purposes: age $<18$ years vs. $18+$ years, BMI underweight vs. all other categories, education $\leq 8$ basic classes vs. any higher grade, housing without amenities vs. partial/full amenities, married vs. all other options, being unemployed vs. all other employment options, consuming fruits, vegetables, dairy products, and coffee daily vs. less than daily.

Measuring bivariate associations, we applied the Pearson Chi-square probe. Logistic regression was used to assess factors associated with continuing versus quitting tobacco use during the pregnancy (significance level was $\mathrm{p} \leq 0.05$ ).

\section{RESULTS}

\section{Sociodemographic Characteristics}

More than 1 in 4 respondents were self-identified as Roma (28.8\%). Deep poverty was prevalent (42.7\%), with the majority of Roma being impoverished (85.1\%). The level of education was generally low: basic 8 classes $34.9 \%$, vocational training $18.1 \%$, secondary school $26.8 \%$, college and university $20.1 \%$. In the Roma subsample, the percentages were similar, but with the vast majority completing 8 classes or less: $86.1 \%, 11.2 \%, 2.7 \%$, and $0.1 \%$. Among the total sample, less than two-thirds (63.1\%) lived in housing with full amenities. In Roma communities, only 1 in 5 women lived in a house with full amenities (19.1\%). About half of the sample $(54.2 \%)$ was married, while $41.8 \%$ were cohabitating. Less than half of the women were employed (44.9\%), with only $6.1 \%$ of Roma reporting being employed.

\section{Association between Poverty, Ethnicity, Smoking and Birth Outcomes}

Among singleton live birth cases $(n=12,471)$, after exclusion of twins $(n=77)$ and triplets $(n=4)$, the overall LBW rate was $8.1 \%$ and the PTB rate was $7.7 \%$.

Table 1 (LBW and PTB rates) shows the impact of ethnicity, economic status and maternal smoking during the pregnancy on LBW and PTB. All differences were significant except those between Roma mothers living in deep poverty versus other Roma mothers living in better economic circumstances. The most favourable outcome of LBW (5.5\%) was among the general population living above the deep poverty level followed closely (5.6\%) by those who were non-smokers. PTB prevalence was equally low $(6.2 \%)$ in the population living above the deep poverty level and in the non-smoking sample. The worst LBW outcome was observed among the subsample of Roma mothers living in deep poverty and who were smoking during the pregnancy; almost 1 in 5 babies born to these women were LBW babies (18.3\%). The highest rate of PTB (13.4\%) were among smoking Roma mothers during the pregnancy, but the outcome was nearly the same (13.3\%) among non-smoking Roma mothers living in deep poverty.

\section{Understanding the Impact of Deep Poverty}

Table 2 (socioeconomic features) shows selected variables summarized and among those in deep poverty versus all other economic categories. The data reveals the high rates of Roma living in deep poverty $(58.0 \%)$ compared to the population as a whole. Moreover, rates of exposure to SHS are almost twice as high for women living in poverty (45.1\%) versus those who do not $(24.7 \%)$. Dietary habits are moderately different in fruits, vegetables and dairy products consumption. Only coffee consumption mounted from the overall $48.8 \%$ to $57.8 \%$.

Table 3 includes only the population living in deep poverty while testing ethnic differences between Roma and all other non-Roma Hungarians. There were 5,038 mothers living in deep poverty of which $12.5 \%(n=632)$ refused to answer the question about ethnicity. Differences were observed in all variables (coffee consumption was the only exception) with Roma women living in deep poverty having, on average, worse outcomes than

Table 1. Low birth weight and preterm birth rates of prenatal maternal tobacco smoking of singleton live born cases among Roma, in deep poverty and by combined stratification of these factors $(N=12,471)$

\begin{tabular}{|c|c|c|c|c|}
\hline Variables & $\begin{array}{l}\text { LBW } \\
\mathrm{n}(\%)\end{array}$ & $\mathrm{p}$-value & $\begin{array}{l}\text { PTB } \\
\mathrm{n}(\%)\end{array}$ & $\mathrm{p}$-value \\
\hline \multicolumn{5}{|l|}{ Whole sample } \\
\hline Roma vs. non-Roma & 394 | 486 (12.9 | 6.4) & $<0.001$ & $315 \mid 514(10.3 \mid 6.8)$ & $<0.001$ \\
\hline Deep poverty vs. all others & $603 \mid 372(12.1 \mid 5.5)$ & $<0.001$ & 484 | 420 (9.6 | 6.2) & $<0.001$ \\
\hline Smoking vs. no smoking & $496 \mid 476(16.0 \mid 5.6)$ & $<0.001$ & $375 \mid 530(12.0 \mid 6.2)$ & $<0.001$ \\
\hline \multicolumn{5}{|l|}{ Roma } \\
\hline Deep poverty vs. all others & $340 \mid 47(13.4 \mid 10.5)$ & 0.095 & $257 \mid 50(10.1 \mid 11.2)$ & 0.481 \\
\hline Smoking vs. no smoking & $269 \mid 120$ (17.6 | 8.3) & $<0.001$ & $205 \mid 106(13.4 \mid 7.3)$ & $<0.001$ \\
\hline $\begin{array}{l}\text { Smoking Roma in deep poverty vs. non-smoking Roma } \\
\text { in deep poverty }\end{array}$ & 239 | $97(18.3$ | 8.3) & $<0.001$ & 174 | 80 (13.3 | 6.8) & $<0.001$ \\
\hline
\end{tabular}

p-values of the Pearson Chi-square test, LBW - low birth weight, PTB - preterm birth 
Table 2. Socioeconomic features of the overall, those in deep poverty and those not in deep poverty among mothers in four underdeveloped Hungarian counties 2009-2012 $(N=12,552)$

\begin{tabular}{|c|c|c|c|c|}
\hline Variable & $\begin{array}{c}\text { Overall } \\
\mathrm{n}(\%)\end{array}$ & $\begin{array}{c}\text { Deep poverty } \\
n(\%)\end{array}$ & $\begin{array}{c}\text { Above deep poverty } \\
\mathrm{n}(\%)\end{array}$ & $\mathrm{p}$-value \\
\hline Ethnicity, Roma vs. non-Roma & $3,004 \mid 7,185(29.5 \mid 70.5)$ & $2,556 \mid 1,850(58.0 \mid 42.0)$ & $448 \mid 5,335(7.7 \mid 92.3)$ & $<0.001$ \\
\hline Age $<18$ vs. $\geq 18$ years & 384 | 11,439 (3.2 | 96.8) & $329 \mid 4,709(6.5 \mid 93.5)$ & $55 \mid 6,730(0.8 \mid 99.2)$ & $<0.001$ \\
\hline BMI underweight vs. all others & $1,101 \mid 10,288(9.7 \mid 90.3)$ & $695 \mid 4,143(14.4 \mid 85.6)$ & $406 \mid 6,145(6.2 \mid 93.8)$ & $<0.001$ \\
\hline $\begin{array}{l}\text { Education } \leq 8 \text { basic classes vs. all } \\
\text { others }\end{array}$ & 4,223 | 7,552 (35.9 | 64.1) & $3,469 \mid 1,543(69.2 \mid 30.8)$ & $754 \mid 6,009$ (11.1 | 88.9) & $<0.001$ \\
\hline $\begin{array}{l}\text { Housing without amenities vs. } \\
\text { partial/full amenities }\end{array}$ & $2,140 \mid 8,975$ (19.3 | 80.7) & 1,917 | 2,792 (40.7 | 59.3) & $223 \mid 6,183(3.5 \mid 80.7)$ & $<0.001$ \\
\hline Married vs. all other family status & $6,220 \mid 5,552(52.8 \mid 47.2)$ & $1,670 \mid 3,344(33.3 \mid 66.7)$ & $4,550 \mid 2,208(67.3 \mid 32.7)$ & $<0.001$ \\
\hline Unemployed vs. employed & $6,592 \mid 5,170(56.0 \mid 44.0)$ & $4.316 \mid 688(86.3 \mid 13.7)$ & $2,276 \mid 4,482(33.7 \mid 66.3)$ & $<0.001$ \\
\hline $\begin{array}{l}\text { Regular smoker vs. non-smoker } \\
\text { prior to pregnancy }\end{array}$ & $4,420 \mid 7,352(37.5 \mid 62.5)$ & $2,488 \mid 2,521(49.7 \mid 50.3)$ & 1,932 | 4,831 (28.6 | 71.4) & $<0.001$ \\
\hline $\begin{array}{l}\text { Second hand smoke by husband } \\
\text { or partner, yes vs. no }\end{array}$ & $2,801 \mid 8,534(24.7 \mid 75.3)$ & $2,144 \mid 2,613(45.1 \mid 54.9)$ & $657 \mid 5,921(10.0 \mid 90.0)$ & $<0.001$ \\
\hline Fruits daily vs. less than daily & $8,319 \mid 3,431$ (70.8 | 29.2) & 2,812 | 2,187 (56.3 | 43.7) & $5,506 \mid 1,244(81.6 \mid 18.4)$ & $<0.001$ \\
\hline Vegetables daily vs. less than daily & $7,200 \mid 4,545(61.3$ | 38.7) & 2,415 | 2,579 (48.4 | 51.6) & $4,785 \mid 1,966(70.9 \mid 29.1)$ & $<0.001$ \\
\hline $\begin{array}{l}\text { Dairy products daily vs. less than } \\
\text { daily }\end{array}$ & 8,537| 3,202 (72.7| 27.3) & $3,064 \mid 1,934$ (61.3 | 38.7) & $5,473 \mid 1,268(81.2$ | 18.8) & $<0.001$ \\
\hline Coffee daily vs. less than daily & $5,667 \mid 5,948(48.8 \mid 51.2)$ & $2,855 \mid 2,086(57.8 \mid 42.2)$ & $2,812 \mid 3,862(42.1 \mid 57.9)$ & $<0.001$ \\
\hline Deliveries 1 vs. 2-14 & $4,946 \mid 6,778$ (42.2 | 57.8) & $1,462 \mid 3,530(29.3 \mid 70.7)$ & $3,484 \mid 3,248(51.8 \mid 48.2)$ & $<0.001$ \\
\hline
\end{tabular}

p-values of the Chi-square test between Deep poverty and Above deep poverty groups, BMI - body mass index

non-Roma women living in deep poverty. Among those in deep poverty, more than half $(56.0 \%)$ of the non-Roma population had education above the basic school compared to only $11.3 \%$ among Roma.

Out of 4,589 women who admitted regular smoking 4,045 $(88.1 \%)$ answered the question of smoking related behaviour after learning they were pregnant. Among them $70.3 \%$ continued the habit. Out of 4,045 women 3,703 answered the question of seeking or not seeking professional help outside MCHS for cessation. Seeking admitted only $82(2.2 \%)$ and 15 quit immediately. Another $23.0 \%$ quit spontaneously, i.e. 832 of 3,621 women who did not seek professional help.

\section{Multivariable Model Predicting Smoking Cessation during Pregnancy}

We conducted a multivariable logistic regression analysis with 12,470 mothers who answered the smoking status question prior to their actual pregnancy (Table 4). Women who continued to smoke were more likely to self-identify as Roma ethnicity $(\mathrm{OR}=1.95,95 \%$ CI $1.38-2.95)$, were more than twice as likely to be undereducated $(\mathrm{OR}=2.66,95 \%$ CI 1.86-3.81), lived in homes that lack partial or full amenities $(\mathrm{OR}=1.48,95 \% \mathrm{CI}$ 1.03-2.12), were living with regularly smoking partner $(\mathrm{OR}=2.07$ $95 \%$ CI 1.51-2.84), and consumed coffee daily $(\mathrm{OR}=1.88,95 \%$ CI 1.37-2.57). The impact of BMI and labour market position were not significant. Factors that increased the likelihood of cessation include being younger ( $\leq 18$ years) $(\mathrm{OR}=0.18,95 \%$ CI $0.11-0.29)$ and being married $(\mathrm{OR}=0.50,95 \%$ CI $0.37-0.68)$. Consuming fruits, vegetables and dairy products daily were also protective factors $(\mathrm{OR}=0.56,95 \% \mathrm{CI} 0.40-0.80 ; \mathrm{OR}=0.69,95 \%$
CI $0.49-0.97 ; \mathrm{OR}=0.66,95 \% \mathrm{CI} 0.48-0.92)$. The first pregnancy was a stronger motivation to quit $(\mathrm{OR}=0.51,95 \% \mathrm{CI} 0.37-0.71)$.

\section{DISCUSSION}

Our data precede Hungary's anti-tobacco legislation of 2012 and the extension of MCHS nurses' competencies for professional tobacco cessation counselling of women during pregnancy. These data reveal important baseline information about tobacco use among pregnant women living in high risk environments of social deprivation based on income poverty and low level of education. Additionally, Roma women are of special concern in Hungary given predominantly anecdotal comments by healthcare personnel about high rates of maternal smoking and the perceived culture that normalizes SHS exposure among pregnant women in Roma families.

Compared with 2012 national average data of female smoking, smoking prevalence among this vulnerable population was more than 1.5 times higher overall and more than two times higher among Roma women. Similarly, more than half of women with the lowest level of education ( $\leq 8$ basic classes) smoked, exceeding the national averages for undereducated females and males. There was an extraordinary high rate of LBW (18.3\%) among the most vulnerable group: smoking pregnant Roma women living in deep poverty. The worst PTB outcome was detected among smoking Roma women living above the deep poverty level. According to a recent study of smoking-attributable adverse outcomes, our results are similar to those of the US non-Hispanic Blacks who represent a disproportionately higher percentage of PTBs (18\%) and LBW cases (22\%) when compared to whites (26). 
Table 3. Socioeconomic features among those living in deep poverty stratified by self-identified Roma $(N=2,556)$ and nonRoma Hungarian ethnicity $(N=1,850)$ in four underdeveloped Hungarian counties 2009-2012

\begin{tabular}{|l|c|c|c|c|}
\hline Variable & \multicolumn{1}{|c|}{$\begin{array}{c}\text { Overall } \\
\mathbf{n}(\%)\end{array}$} & $\begin{array}{c}\text { Roma } \\
\mathbf{n}(\%)\end{array}$ & $\begin{array}{c}\text { Non-Roma } \\
\mathbf{n}(\%)\end{array}$ & p-value \\
\hline Age <18 vs. $\geq 18$ years & $298 \mid 4,108(6.8 \mid 93.2)$ & $239 \mid 2,317(9.4 \mid 90.6)$ & $59 \mid 1,1791(3.2 \mid 96.8)$ & $<0.001$ \\
\hline BMl underweight vs. all others & $621 \mid 3,632(14.6 \mid 85.4)$ & $416 \mid 2,046(16.9 \mid 83.1)$ & $205 \mid 1,586(11.4 \mid 88.6)$ & $<0.001$ \\
\hline Education $\leq 8$ basic classes vs. all others & $3,069 \mid 1,321(69.9 \mid 30.1)$ & $2,255 \mid 286(88.7 \mid 11.3)$ & $814 \mid 1,035(44.0 \mid 56.0)$ & $<0.001$ \\
\hline $\begin{array}{l}\text { Housing without amenities vs. partial/full } \\
\text { amenities }\end{array}$ & $1,714 \mid 2,424(41.4 \mid 58.6)$ & $1,354 \mid 1,047(56.4 \mid 43.6)$ & $360 \mid 1,377(20.7 \mid 79.3)$ & $<0.001$ \\
\hline Married vs. all other family status & $1,439 \mid 2,948(32.8 \mid 2.948)$ & $629 \mid 1,916(24.7 \mid 75.3)$ & $810 \mid 1,032(44.0 \mid 56.0)$ & $<0.001$ \\
\hline Unemployed vs. employed & $3,797 \mid 586(86.6 \mid 13.4)$ & $2,444 \mid 99(96.1 \mid 3.9)$ & $1,353 \mid 487(73.5 \mid 26.5)$ & $<0.001$ \\
\hline $\begin{array}{l}\text { Regular smoker vs. non-smoker prior to } \\
\text { pregnancy }\end{array}$ & $2,163 \mid 2,223(49.3 \mid 50.7)$ & $1,336 \mid 1,206(52.6 \mid 47.4)$ & $827 \mid 1,017(44.8 \mid 55.2)$ & $<0.001$ \\
\hline $\begin{array}{l}\text { Second hand smoke by husband or } \\
\text { partner, yes vs. no }\end{array}$ & $1,670 \mid 2,285(45.0 \mid 55.0)$ & $1,280 \mid 1,143(52.8 \mid 47.2)$ & $590 \mid 1,142(34.1 \mid 65.9)$ & $<0.001$ \\
\hline Fruits daily vs. less than daily & $2,418 \mid 1,955(55.3 \mid 44.7)$ & $1,205 \mid 1,333(47.5 \mid 52.5)$ & $1,213 \mid 622(66.1 \mid 33.9)$ & $<0.001$ \\
\hline Vegetables daily vs. less than daily & $2,088 \mid 2,284(47.8 \mid 52.2)$ & $1,042 \mid 1,495(41.1 \mid 58.9)$ & $1,046 \mid 789(57.0 \mid 43.0)$ & $<0.001$ \\
\hline Dairy products daily vs. less than daily & $2,683 \mid 1,736(60.3 \mid 39.7)$ & $1,371 \mid 1,146(54.1 \mid 45.9)$ & $1,267 \mid 572(68.9 \mid 31.1)$ & $<0.001$ \\
\hline Coffee daily vs. less than daily & $2,480 \mid 1,849(57.3 \mid 42.7)$ & $1,465 \mid 1,044(58.4 \mid 41.6)$ & $1,015 \mid 805(55.8 \mid 44.2)$ & 0.085 \\
\hline Deliveries 1 vs. 2-14 & $1,276 \mid 3,090(29.2 \mid 70.8)$ & $733 \mid 1,803(28.9 \mid 71.1)$ & $543 \mid 1,287(29.7 \mid 70.3)$ & 0.582 \\
\hline
\end{tabular}

p-values of the Chi-square test between Roma and Non-Roma groups, BMI - body mass index

Lower SES is one of the main social factors associated with adverse birth outcomes. The mechanisms of action have been hypothesized in biomedical terms as stress-induced increases in cortisol levels $(27,28)$, in social terms as less social support and financial resources, more family problems, and less residential stability, although this profile may vary by country (29). One of the major factors is that lower SES women continue to smoke during pregnancy $(2,28)$. We demonstrated that socioeconomic deprivation is highly concentrated among the Roma minority. Roma ethnicity is generally considered a proxy for negative health status in underdeveloped regions, but it is important to recognize that Roma is more likely a proxy for socioeconomic deprivation and such deprivation is the major driver in poor health (30). Nonetheless, it is well-documented that nicotine dependence and smoking persistence are, at least in part, heritable and are determined by a complex interplay of polygenic and environmental factors. The most robust evidence for specific genetic influences on nicotine dependence is found in studies of genetic variation in nicotine-metabolizing enzymes (31). As a relevant study definitely excluded ethnicity as independent variable in Roma research projects (32), we analysed separately 13 demographic and SES variables of Roma and non-Roma Hungarian subsamples in the same deep poverty circumstances. Except for coffee consumption and former deliveries, all other differences were significant indicating that Roma have socio-culturally different behavioural patterns even in the same socioeconomic situation. There were significantly more regular smoking women prior to the pregnancy (52.6\% vs. $44.8 \%)$ and greater SHS exposure (52.8\% vs. $34.1 \%)$.

As MCHS nurses were recently mandated to practise professionally the minimal intervention programme of smoking cessation, we can use $23.0 \%$ as a baseline estimate for spontaneous cessation for determining the effectiveness of the new MCHS intervention. In a recent study to reduce smoking among pregnant women recruited from rural medical practices in the USA, $9.8 \%$ of women quit smoking in control condition compared to $28.0 \%$ in the intervention group. Women in the intervention group received the 5A's (Ask, Advise, Assess, Assist, Arrange) by trained health educators in professional settings (33).

Our multivariable analysis shows clearly the main intervention options for a successful programme. The probability of continued smoking during pregnancy among Roma women was 2-times higher. Putting aside theoretical considerations about ethnicity, based on this outcome, it seems reasonable to use this variable at least to help identifying the highest risk population. We realized the positive impact of younger age, marriage, and other healthy lifestyle factors (e.g., fruit and vegetable consumption). The robust positive impact of the first pregnancy emphasizes the significance of using this teachable moment in all prevention programmes. However, the serious negative impact of lacking higher education, and SHS generated by husband or partner in at home confined spaces indicates the need for social interventions in the highest risk communities.

\section{CONCLUSIONS}

This study provides, for the first time, evidence about the multiple interrelations of factors among being a member of a disadvantaged ethnic minority as it relates to smoking during pregnancy. Limitations of our study relate to the reliance on self-reported data (which would bias our results towards rather than away from the null, ultimately underestimating effects). In addition, it is difficult to disentangle the influence of supportive social environments and the impact of general medical care on smoking behaviour during pregnancy. Medical professionals (like MCHS nurses in our research) generally ask their patients about substance use and try to persuade them e.g. to quit tobacco smoking. However, these provide a unique opportunity to estimate 
Table 4. Multivariable logistic regression model of factors contributing to smoking cessation during the pregnancy $(N=1,727)$

\begin{tabular}{|l|c|c|c|c|}
\hline \multirow{2}{*}{ Variables } & \multirow{2}{*}{ OR } & \multicolumn{2}{|c|}{$95 \% \mathrm{Cl}$} & \multirow{2}{*}{$\mathrm{p}$-value } \\
\cline { 3 - 4 } & & Lower & Upper & $<0.001$ \\
\hline Ethnicity, Roma vs. non-Roma & 1.95 & 1.38 & 2.95 & $<.29$ \\
\hline Age <18 vs. $\geq 18$ years & 0.18 & 0.11 & 1.19 & 0.001 \\
\hline BMl underweight vs. all others & 0.79 & 0.53 & 3.81 & $<0.001$ \\
\hline Education $\leq 8$ basic classes vs. all others & 2.66 & 1.86 & 2.12 & 0.034 \\
\hline Housing without amenities vs. partial/full amenities & 1.48 & 1.03 & 0.68 & $<0.001$ \\
\hline Married vs. all other family status & 0.50 & 0.37 & 1.84 & 0.324 \\
\hline Unemployed vs. employed & 1.23 & 0.82 & 2.84 & $<0.001$ \\
\hline Second hand smoke by husband or partner, yes vs. no & 2.07 & 1.51 & 0.80 & 0.001 \\
\hline Fruits daily vs. less than daily & 0.56 & 0.40 & 0.97 & 0.034 \\
\hline Vegetables daily vs. less than daily & 0.69 & 0.49 & 0.92 & 0.015 \\
\hline Dairy products daily vs. less than daily & 0.66 & 0.48 & 2.57 & $<0.001$ \\
\hline Coffee daily vs. less than daily & 1.88 & 1.37 & 0.71 & $<0.001$ \\
\hline Deliveries 1 vs. 2-14 & 0.51 & 0.37 & & \\
\hline
\end{tabular}

the real impact of a mandatory training programme for registered nurses through robust baseline data collection.

Tailoring professional cessation programmes for pregnant women is a high priority to reduce tobacco-related adverse obstetrical outcomes in the highest risk population. Locally adjusted complex socioeconomic, sociocultural and public health programmes are needed for ameliorating the high smoking rates of special ethnic minorities living in disadvantaged circumstances.

\section{Acknowledgements}

The authors owe special thanks to the members of the Maternity and Child Health Service. The study would not have been possible without their close and devoted cooperation.

\section{Conflict of Interests}

None declared

\section{Sponsorship}

This publication was based on the research project supported by the Fogarty International Centre, the National Cancer Institute and the National Institutes on Drug Abuse within the National Institutes of Health (Grant Number 1 R01 TW007927-01).

\section{Adherence to Ethical Recommendations}

The authors assert that all procedures contributing to this work comply with the ethical standards of the relevant national and institutional committees on human experimentation and with the Helsinki Declaration of 1975 , as revised in 2008

\section{REFERENCES}

1. Ko TJ, Tsai LY, Chu LC, Yeh SJ, Leung C, Chen CY, et al. Parental smoking during pregnancy and its association with low birth weight, small for gestational age, and preterm birth offspring: a birth cohort study. Pediatr Neonatol. 2014 Feb;55(1):20-7.

2. Räisänen S, Kramer MR, Gissler M, Saari J, Hakulinen-Viitanen T, Heinonen S. Smoking during pregnancy was up to $70 \%$ more common in the most deprived municipalities - a multilevel analysis of all singleton births during 2005-2010 in Finland. Prev Med. 2014 Oct;67:6-11.
3. Vivilaki VG, Diamanti A, Tzeli M, Patelarou E, Bick D, Papadakis S, et al. Exposure to active and passive smoking among Greek pregnant women. Tob Induc Dis. 2016 Apr;14:12. doi: 10.1186/s12971-016-0077-8.

4. Paulik E, Nagymajtényi L, Easterling D, Rogers T. Smoking behaviour and attitudes of Hungarian Roma and non-Roma population towards tobacco control policies. Int J Public Health. 2011 Oct;56(5):485-91.

5. Bobak M, Dejmek J, Solansky I, Sram RJ. Unfavourable birth outcomes of the Roma women in the Czech Republic and the potential explanations: a population-based study. BMC Public Health. 2005 Oct 10;5:106. doi:10.1186/1471-2458-5-106.

6. Rambousková J, Dlouhý P, Krízová E, Procházka B, Hrncírová D, Ande M. Health behaviors, nutritional status, and anthropometric parameters of Roma and non-Roma mothers and their infants in the Czech Republic. J Nutr Educ Behav. 2009 Jan-Feb;41(1):58-64

7. Balázs P, Rákóczi I, Grenczer A, Foley KL. Birth-weight differences of Roma and non-Roma neonates - public health implications from a population-based study in Hungary. Cent Eur J Public Health. 2014 Mar;22(1):24-8.

8. Meghea CI, Rus D, Rus IA, Summers Holtrop J, Roman L. Smoking during pregnancy and associated risk factors in a sample of Romanian women. Eur J Public Health. 2012 Apr;22(2):229-33.

9. European Commission. An EU framework for national Roma integration strategies up to 2020: Communication from the Commission to the European Parliament, the Council, the European Economic and Social Committee and the Committee of the Regions [Internet]. Brussels; 2011 [cited 2018 Aug 31]. Available from: https://www.google.com/ search?q=An+EU+framework + for + national + Roma + integration + strate gies + up + to $+2020 \&$ ie $=u t f-8 \&$ oe $=$ utf- $8 \&$ client $=$ firefox-b.

10. Census National Data, 2011 [Internet]. Budapest: Hungarian Central Statistical Office; 2014 [cited 2018 Aug 31]. Available from: http:// www.ksh.hu/docs/hun/xftp/idoszaki/nepsz2011/nepsz_09_2011.pdf. (In Hungarian.)

11. World Health Organization. WHO Framework Convention on Tobacco Control [Internet]. Geneva: WHO; 2003 [cited 2018 Aug 31]. Available from: http://www.who.int/tobacco/framework/WHO_FCTC_english. pdf.

12. Lomnici Z. Hungary's legal regulation of smoking from the Austro-Hungarian conciliation till present days. In: Increasing capacity for tobacco research in Hungary, 2008-2013. Budapest: Institute for the History of Hungarian Séciences; 2013. p. 215-32.

13. WHO Regional Office for Europe. Tobacco control in practice. Article 8: Protection from exposure to tobacco smoke: the story of Hungary [Internet]. Copenhagen: WHO; 2014 [cited 2018 Aug 31]. Available from: http://www.euro.who.int/_data/assets/pdf_file/0020/263333/ Tobacco-control-in-practice-Article-8-Protection-from-exposure-totobacco-smoke-the-story-of-Hungary.pdf?ua=1

14. Vicedo-Cabrera AM, Schindler C, Radovanovic D, Grize L, Witassek F, Dratva J, et al. Benefits of smoking bans on preterm and early-term 
births: a natural experimental design in Switzerland. Tob Control. 2016 Dec;25(e2):e135-41.

15. World Health Organization, Regional Office for Europe. Hungary releases new data on the social burden of smoking [Internet]. Copenhagen: WHO Regional Office for Europe; 2012 [cited 2018 Aug 31]. Available from: http://www.euro.who.int/en/countries/hungary/news/news/2012/06/ hungary-releases-new-data-on-the-social-burden-of-smoking.

16. National Institute for Health Development, Hungarian Focal Point for Tobacco Control. Hungarian and foreign data \& statistics [Internet]. 2014 [cited 2018 Aug 31]. Available from: http://www.fokuszpont.dohanyzasvisszaszoritasa.hu/en/content/hungarian-and-foreign-data-statistics.

17. Central Statistical Office of Hungary [Internet]. 2014 [cited 2018 Aug 31]. Available from: http://www.ksh.hu/interaktiv/terkepek/mo/gdp_eng. html.

18. Rice VH, Stead LF. Nursing interventions for smoking cessation. Cochrane Database Syst Rev. 2008 Jan 23;(1):CD001188. doi: 10.1002/14651858. CD001188.pub3.

19. Kintz T, Pryor C, Shemami H, Al-Oballi Kridli S. Nursing interventions to promote smoking cessation during pregnancy: An integrative review. J Nurs Educ Pract. 2014;4(9):77-90.

20. Lawson PJ, Flocke SA, Casucci B. Development of an instrument to document the 5A's for smoking cessation. Am J Prev Med. 2009 Sep;37(3):248-54.

21. World Health Organization. Toolkit for delivering the 5A's and 5R's brief tobacco interventions in primary care. Geneva: WHO; 2014.

22. Fiore MC, Jaén CR, Baker TB, Bailey WC, Benowitz NL, Curry SJ, et al. Treating Tobacco Use and Dependence: 2008 Update. Clinical Practice Guideline. Rockville: U.S. Department of Health and Human Services, Public Health Service; 2008.

23. Ockene J, Ma Y, Zapka J, Pbert L, Valentine Goins K, Stoddard A. Spontaneous cessation of smoking and alcohol use among low-income pregnant women. Am J Prev Med. 2002 Oct;23(3):150-9.

24. Morasco BJ, Dornelas EA, Fischer EH, Oncken C, Lando HA. Spontaneous smoking cessation during pregnancy among ethnic minority women: a preliminary investigation. Addict Behav. 2006 Feb;31(2):203-10.
25. TÁRKI Social Research Institute Inc. Inequalities and polarization in the Hungarian society [Internet]. Budapest, TÁRKI; 2013 [cited 2018 Aug 31]. Available from: http://www.tarki.hu/hu/research $/ \mathrm{hm} / \mathrm{moni}-$ tor2012_teljes.pdf.

26. Mohlman MK, Levy DT. Disparities in maternal child and health outcomes attributable to prenatal tobacco use. Matern Child Health J. 2016 Mar;20(3):701-9.

27. Vianna P, Bauer ME, Dornfeld D, Chies JA. Distress conditions during pregnancy may lead to pre-eclampsia by increasing cortisol levels and altering lymphocyte sensitivity to glucocorticoids. Med Hypotheses. 2011 Aug;77(2):188-91.

28. LeWinn KZ, Stroud LR, Molnar BE, Ware JH, Koenen KC, Buka SL. Elevated maternal cortisol levels during pregnancy are associated with reduced childhood IQ. Int J Epidemiol. 2009 Dec;38(6):1700-10.

29. Pregnancy and postpartum smoking cessation. In: Samet JM, Yoon SY, editors. Gender, women, and the tobacco epidemic. Geneva: WHO; 2010. p. $175-88$.

30. Vokó Z, Csépe P, Németh R, Kósa K, Kósa Z, Széles G, et al. Does socioeconomic status fully mediate the effect of ethnicity on the health of Roma people in Hungary? J Epidemiol Community Health. 2009 Jun;63(6):455-60.

31. Lerman CE, Schnoll RA, Munafò MR. Genetics and smoking cessation improving outcomes in smokers at risk. Am J Prev Med. 2007 Dec;33(6 Suppl):S398-405.

32. Kósa K, Lénárt B, Adány R. Health status of the roma population in Hungary. Orv Hetil. 2002 Oct 27;143(43):2419-26. (In Hungarian.)

33. Bailey BA. Effectiveness of a pregnancy smoking intervention: The Tennessee Intervention for Pregnant Smokers Program. Health Educ Behav. 2015 Dec;42(6):824-31.

Received January 27, 2017 Accepted in revised form August 31, 2018 